\title{
A peptide-mediated targeting gene delivery system for malignant glioma cells
}

This article was published in the following Dove Press journal:

International Journal of Nanomedicine

23 September 2013

Number of times this article has been viewed

\section{Chuanwei Wang ${ }^{1,2, *}$ \\ Liping Ning ${ }^{3, *}$ \\ Hongwei Wang ${ }^{1,2, *}$ \\ Zaijun Lu ${ }^{4}$ \\ Xingang $\mathrm{Li}^{1,2}$ \\ Xiaoyong Fan ${ }^{5}$ \\ Xuping Wang ${ }^{6}$ \\ Yuguang Liu ${ }^{1,2}$}

'Department of Neurosurgery, Qilu Hospital of Shandong University, Jinan, People's Republic of China;

${ }^{2}$ Brain Science Research Institute of Shandong University, Jinan, People's Republic of China; ${ }^{3}$ Department of Rehabilitation, Provincial Hospital Affiliated to Shandong University, Jinan, People's Republic of China; ${ }^{4}$ School of Chemistry and Chemical Engineering of Shandong University, Jinan, People's Republic of China; ${ }^{5}$ Department of Neurosurgery, Shandong Qianfoshan Hospital Affiliated to Shandong University, Jinan, People's Republic of China; ${ }^{6}$ Key Laboratory of Cardiovascular Remodeling and Function Research, Chinese Ministry of Education and Chinese Ministry of Public Health, Qilu Hospital of Shandong University, Jinan, People's Republic of China

*These authors contributed equally to this work
Correspondence: Yuguang Liu

Department of Neurosurgery,

Qilu Hospital of Shandong University, Jinan 2500 I2, People's Republic of China

$\mathrm{Tel}+8653182166621$

Fax +86 53I 88382060

Email lyg3000@126.com
Abstract: Glioblastoma multiforme (GBM) is the most common and malignant glioma. Although there has been considerable progress in treatment strategies, the prognosis of many patients with GBM remains poor. In this work, polyethylenimine (PEI) and the VTWTPQAWFQWV (VTW) peptide were modified and synthesized into GBM-targeting nanoparticles. The transfection efficiency of U-87 (human glioblastoma) cells was evaluated using fluorescence microscopy and flow cytometry. Cell internalization was investigated to verify the nanoparticle delivery into the cytoplasm. Results showed that the methods of polymer conjugation and the amount of VTW peptide were important factors to polymer synthesis and transfection. The PEI-VTW ${ }_{20}$ nanoparticles increased the transfection efficiency significantly. This report describes the use of VTW peptide-based PEI nanoparticles for intracellular gene delivery in a GBM cell-specific manner.

Keywords: glioblastoma, polyethylenimine, nanoparticles, drug-delivery systems, gene transfer techniques

\section{Introduction}

Glioblastoma multiforme (GBM) is a severely malignant glioma, which accounts for approximately $1 / 5-1 / 4$ of the primary intracranial malignancies. ${ }^{1,2}$ Despite the progress that has been made in cancer treatment, the prognosis for a portion of patients with GBM remains poor, with a median survival of approximately 3-15 months., ${ }^{1,3-5}$ Over the past few decades, gene therapies, including the use of suicide genes ${ }^{6-8}$ and small interfering RNA ( However, one obstacle to gene therapy is the lack of an effective, safe, and targeting vector. ${ }^{6,7}$ Viral vectors have higher transfection efficiency than nonviral ones, but they also have immunogenicity and potential oncogenicity implications. ${ }^{6,7}$ Nonviral vectors made of polymers, such as polyethylenimine (PEI), poly-L-lysine (PLL), and chitosan, have been used increasingly widely because of their biosafety, convenience of preparation, and stability. ${ }^{11-13}$ PEI is considered one of the good nonviral vectors, and it shows higher transfection efficiency than PLL and chitosan. ${ }^{14-16}$ However, the PEI/DNA nanoparticles are still less effective than viral vectors and have no targeting effect. ${ }^{14,16,17}$

Certain molecules overexpressed on the surface of some tumor cells, including fibroblast growth factor receptors and epidermal growth factor receptors, have been used to improve the penetration of drugs or genetic products into tumor cells. ${ }^{18-20}$ However, these molecules are not specific enough because they are also expressed on some normal cells, although not to the same extent as on tumor 
cells. Phage peptide display is one technique that can be used to isolate peptides with targeting effects on specific cells. ${ }^{21}$ One peptide recently found by phage display, with a sequence of VTWTPQAWFQWV (VTW), showed particularly strong binding to human glioblastoma cell lines, but quite weak binding to normal human astrocytes and other cell lines. $^{22}$

In this study, we constructed PEI/DNA nanoparticles conjugated with VTW to investigate whether these nanoparticles could specifically increase the transfection efficiency of malignant glioblastoma cells.

\section{Materials and methods Materials}

Branched PEI (25 kDa), N,N-Dimethylformamide (DMF), PLL (70-150 kDa) and trinitrobenzenesulfonic acid (TNBS) were purchased from Sigma-Aldrich (St Louis, MO, USA). N-succinimidyl 3-(2-pyridyldithio)-propionate (SPDP) was purchased from Thermo Fisher Scientific (Waltham, MA, USA). The PD-10 desalting columns were purchased from GE Healthcare (Little Chalfont, Buckinghamshire, UK). Cell Counting Kit-8 (CCK-8) was purchased from Dojindo (Mashikimachi, Kamimashiki-gun Kumamoto, Japan). The VTW peptide with a cysteine residue at the C-terminus, with a purity of $>95 \%$, was purchased from Science Peptide Biological Technology Co, LTD (Shanghai, People's Republic of China). The peptide was stored in small aliquots at $-80^{\circ} \mathrm{C}$. The fluorescein isothiocyanate (FITC) nucleic acid labeling kit was purchased from Mirus Bio (Madison, WI, USA). Antibiotics, L-glutamine, $0.25 \%$ trypsin, fetal bovine serum (FBS), minimum essential medium (MEM), Neuralbasal ${ }^{\circledR}$ medium, 2.5S nerve growth factor, B27 supplement, Lipofectamine $^{\circledR}$, and phosphate-buffered saline (PBS) were purchased from Invitrogen Life Technologies, (Carlsbad, CA, USA). Other chemical reagents were commercially available and of analytical grade.

\section{Cell culture}

The U-87 (human glioblastoma) cell line was purchased from the Cell Bank of the Chinese Academy of Sciences (Shanghai, People's Republic of China). The T98G (human glioblastoma), U251 (human glioma), A549 (human lung adenocarcinoma), and PC12 (rat adrenal gland pheochromocytoma) cell lines were gifts from the Key Laboratory of Qilu Hospital of Shandong University, Jinan, People's Republic of China. All cells were cultured in MEM supplemented with 10\% FBS, 2 mM L-glutamine, and 1\% penicillin-streptomycin.
The neural cells from rat cerebral cortex were obtained and cultured as previously described, with slight differences. ${ }^{23}$ The animal experiments complied with the experimental animal ethical approval and inspection of the Research Subject Review Board at Shandong University, People's Republic of China. The 1-day-old neonatal Sprague Dawley (SD) rats were obtained from the Lab Animal Center of Shandong University, euthanized using the inhalant isoflurane, and then decapitated. After the cranium and meninges were removed, the cerebral cortex was dissected in a sterile environment and dissociated with $0.25 \%$ trypsin for $10-15 \mathrm{~min}$ at $37^{\circ} \mathrm{C}$. Cells were seeded in 24-well plates coated with $0.1 \mathrm{mg} / \mathrm{mL}$ poly-L-lysine at a density of $2 \times 10^{5}$ cells/well in Neurobasal medium supplemented with $20 \mathrm{ng} / \mathrm{mL}$ nerve growth factor, 2\% B27 supplement, 2 mM L-glutamine, and $1 \%$ penicillin-streptomycin.

\section{Plasmid DNA (pDNA) preparation}

The enhanced green fluorescent protein plasmid (pEGFP) was transfected into Escherichia coli DH5 $\alpha$ competent cells (Tiangen, Beijing, People's Republic of China) and amplified. DNA purification was performed using an EndoFree Plasmid Kit (Tiangen), following the manufacturer's instructions. The concentration and purity of the plasmid preparation were measured by ultraviolet (UV) spectrophotometer (DU800; Beckman Coulter, Brea, CA, USA). Plasmid solutions with absorbance ratios $(260 \mathrm{~nm} / 280 \mathrm{~nm})$ between 1.8 and 2.0 were used.

\section{Synthesis of VTW-modified PEI copolymers}

Three types of VTW-modified PEI nanoparticles were made to investigate whether the amount of VTW conjugated with PEI influenced the transfection efficiency. PEI ( $1 \mu \mathrm{mol})$ dissolved in $1 \mathrm{~mL}$ hepes-buffered saline (HBS) $(0.5 \mathrm{M} \mathrm{NaCl}$, 20 mM 4-(2-hydroxyethyl)-1-piperazineethanesulfonic acid [HEPES], pH 7.4) was mixed with $100 \mu \mathrm{L}$ SPDP (100 mM in DMF) and incubated under argon protection for 2 hours at room temperature (RT). This pyridyldithio (PDT)-activated PEI was named PEI-PDT ${ }_{10}$. For the other two groups (PEI$\mathrm{PDT}_{20}$ and PEI-PDT ${ }_{40}$ ), the same protocol was used, except the volumes of SPDP used were $200 \mu \mathrm{L}$ and $400 \mu \mathrm{L}$, respectively. The PEI-PDT polymers were purified using a PD-10 column, according to the manufacturer's instructions. The VTW peptide was dissolved in $100 \mu \mathrm{L}$ DMF and $900 \mu \mathrm{L}$ guanidine hydrochloride $(\mathrm{GnHCl})$ buffer $(6 \mathrm{M} \mathrm{GnHCl}, 0.5$ $\mathrm{M} \mathrm{NaCl}, 20 \mathrm{mM}$ HEPES, $\mathrm{pH}$ 7.4). Then, the VTW solution with different molar ratios to PEI-PDT (10:1, 20:1, 40:1) 
was dropped into three types of PEI-PDT solutions and incubated for 2 hours at RT. The PDT residue of PEI-PDT was displaced by the sulfhydryls of the cysteine residue of VTW, forming the VTW-modified PEI copolymers (PEI-VTW, here abbreviated as $\mathrm{PV}_{10}, \mathrm{PV}_{20}$ and $\left.\mathrm{PV}_{40}\right)$. Subsequently, the copolymers were purified separately by using a $30 \mathrm{kDa}$ cutoff filter (Vivaspin 2; Sartorius, Göttingen, Germany) and centrifugation at $12,000 \mathrm{Xg}$ for 20 minutes. The concentrations of PEI-VTW in the samples were measured by TNBS assay as described previously ${ }^{24}$ and with the pyridine-2-thione assay. The level of SPDP-modification was determined by measuring the absorbance of pyridine-2-thione at $343 \mathrm{~nm}$. All solutions were filtered through $0.22 \mu \mathrm{m}$ Merck Millipore (Billerica, MA, USA) membranes and stored at $-80^{\circ} \mathrm{C}$.

\section{Preparation of PV nanoparticles}

The $\mathrm{PV}_{10}, \mathrm{PV}_{20}$, and $\mathrm{PV}_{40}$ copolymer solutions were separately diluted with hepes-buffered glucose (HBG) (20 mM HEPES, 5\% w/v glucose, $\mathrm{pH} 7.4$ ) and incubated at RT for 5 minutes. Then, the pDNA solution $(0.1 \mathrm{mg} / \mathrm{mL})$ was mixed with different copolymer solutions separately by vortexing for 30 seconds and incubated for 30 minutes at RT at ratios of nitrogen in PEI amino residues to phosphates of DNA ( $\mathrm{N} / \mathrm{P}$ ratios) ranging from 1 to 10 . The $\mathrm{pDNA}$ was condensed with the PV copolymers by electrostatic force and formed into nanoparticles. The PEI nanoparticles were made by the same procedure.

\section{Characterization of PV nanoparticles}

\section{Particle size and zeta potential}

The particle size and surface charge of nanoparticles in HBG were measured with a Delsa ${ }^{\mathrm{TM}}$ Nano (Beckman Coulter) equipped with a standard capillary electrophoresis cell and dynamic light scattering. All the nanoparticles were measured in HBG buffer ( $\mathrm{pH} 7.4$, ionic strength $0.02 \mathrm{~mol} \cdot \mathrm{dm}^{-3}$ ) at RT. The measurements were performed at least in triplicate.

\section{Transmission electron microscopy (TEM) imaging}

One drop of suspension was placed on carbon holey film on a copper TEM grid and stained with $2 \%$ phosphotungstic acid solution for 20 seconds. The grid was allowed to dry for 10 minutes and then examined with a JEM-200CX TEM (JEOL, Tokyo, Japan).

\section{Agarose gel electrophoresis assay}

The ability to condense plasmid DNA of PEI and PV nanoparticles was examined with agarose gel electrophoresis. Electrophoresis was carried out with $1.0 \%$ agarose gels at
$100 \mathrm{~V}$ for 30 minutes in Tris-acetate-ethylenediaminetetraacetic acid (EDTA) (TAE) buffer (40 mM Tris-hydrogen chloride, $1 \mathrm{v} / \mathrm{v} \%$ acetic acid and $1 \mathrm{mM}$ EDTA). The retardation of the nanoparticles was visualized by staining with ethidium bromide and illuminating with UV using a FluorChem ${ }^{\text {TM9900 }}$ (Cell Biosciences, Heidelberg, VIC, Australia).

\section{Nuclear magnetic resonance (NMR) analysis}

The 1H NMR spectra of copolymers was determined by an AVANCE (300 MHz) NMR spectrometer (Bruker, Billerica, MA, USA) equipped with a $5 \mathrm{~mm}$ boadband oserve $(\mathrm{BBO})$ probe at $\mathrm{RT}$ with a 2 -second relaxation delay.

\section{In vitro transfection studies}

\section{Fluorescence microscopy}

The U-87, T98G, and U251 cells were seeded into 24-well plates at a density of $1 \times 10^{5}$ cells per well and were rinsed with fresh MEM when they grew to $70 \%-80 \%$ confluence. Then, the freshly prepared nanoparticles, with $1.0 \mu \mathrm{g}$ of pEGFP at an N/P ratio of 10, were added to the cells and incubated in $500 \mu \mathrm{L}$ serum-free MEM at $37^{\circ} \mathrm{C}$ for 5 hours. Subsequently, the transfection medium was replaced with complete culture medium, and the cells were incubated for an additional 24 hours. Then, the images were captured with a fluorescence microscope (Olympus BX-51). PEI/ DNA nanoparticles were also prepared at an N/P ratio of 10:1. Lipofectamine-DNA complexes were used as positive control and naked DNA as the negative control. Nanoparticles made of $\mathrm{PV}_{20}$ were incubated with A549, PC12, and neural cells under the same transfection conditions. The influence of serum on transfection was examined by adding $10 \%$ FBS to the incubation medium in two other groups of $\mathrm{PV}_{20}$ nanoparticles and Lipofectamine. All the experiments were performed at least in triplicate.

\section{Flow cytometry}

U-87 cells were seeded at a density of $3 \times 10^{5}$ cells/well in 6-well plates. Transfection procedures were as described above, but the dose of nanoparticles was three times larger. Nanoparticles were delivered to each well in $1.5 \mathrm{~mL}$ MEM and incubated for 5 hours. Then, the medium was replaced with fresh culture medium. After 24 hours, the cells were collected, washed twice with PBS, and resuspended in PBS. Flow cytometry was performed with a FACS-Calibur (BD Biosciences, San Jose, CA, USA). Transfection efficiency was then assessed in cell counts of 10,000 per sample by analyzing for EGFP fluorescence using BD CellQuest ${ }^{\mathrm{TM}}$ Pro (Version 
5.2.1) (BD Biosciences). The assessments were performed at least in triplicate.

\section{Internalization of nanoparticles}

The cellular uptake experiment of the nanoparticles loaded with FITC-labeled plasmid was performed to test the internalization ability and lysosomal escape ability of the $\mathrm{PV}_{20}$ nanoparticles. Fluorescent labeling of the pDNA was carried out using Label $\mathrm{IT}^{\circledR}$ Kits (Mirus Bio) according to the manufacturer's instructions. The labeled DNA was stored at $-20^{\circ} \mathrm{C}$ and protected from light. Lysosomes were marked by Lyso-Tracker Red (Beyotime, Haimen, People's Republic of China) to verify the location of the nanoparticles in the cytoplasm. The transfection of the U-87 cells was carried out according to the procedure described above. After 3 hours' incubation, the cells were washed twice with PBS. Images of the cells were captured with a LSM710-confocal laser scanning microscope (Carl Zeiss, Oberkochen, Germany).

\section{Competition assay}

Cells were pre-incubated at $37^{\circ} \mathrm{C}$ for 1 hour with a 1,000 molar excess of free VTW peptide compared with peptide conjugated to the $\mathrm{PV}_{20}$ nanoparticles. Then, the internalization experiment and microscopy with $\mathrm{PV}_{20}$ nanoparticles were performed as described above.

\section{Cytotoxicity assay}

Cytotoxicity was determined using a CCK-8 Assay Kit according to the manufacturer's instructions. Transfection procedures were as described above but in 96-well plates. The absorbance at $450 \mathrm{~nm}$ was measured using a microplate reader (Thermo Fisher Scientific). Each evaluation was performed at least in triplicate.

\section{Statistical analysis}

Data in this study were calculated as the mean \pm standard deviation. One-way analysis of variance (ANOVA) and a Tukey's post hoc test were used. A $P$-value less than 0.05 was considered statistically significant.

\section{Results}

\section{Characteristics of nanoparticles}

The yield of polymers was $78 \%-81 \%$ according to the TNBS assay. The actual ratio of activated amines in PEI was a little lower than the theoretical ratio (PEI-PDT $_{10}, 7.7 \pm 0.35$; PEI$\mathrm{PDT}_{20}, 16.1 \pm 1.06$; PEI-PDT $40,33.6 \pm 1.63$ ) according to the pyridine-2-thione assay. The nanoparticles in all groups were spherical under TEM (Figure 1A-D). Nanoparticle size and zeta potential were measured to describe the physical features of the nanoparticles at an N/P ratio of 10 (Figure 1E). The PEI/ DNA nanoparticle was $69.8 \pm 5.71 \mathrm{~nm}$ in diameter and the zeta potential was $27.2 \pm 1.62 \mathrm{mV}$. The polydispersity indices of PEI, $\mathrm{PV}_{10}, \mathrm{PV}_{20}$, and $\mathrm{PV}_{40}$ nanoparticles were $0.273,0.165$, 0.291 , and 0.212 , respectively. The PV nanoparticles were larger than the PEI nanoparticles and had lower zeta potential values. In agarose gel electrophoresis, uncomplexed DNA migrated in the lane toward the positive terminal, whereas completely complexed DNA was retained in the loading well. The unmodified PEI formed complete complexes with pDNA at an N/P of 2 (Figure $1 \mathrm{Fc}$ ), whereas $\mathrm{PV}_{10}, \mathrm{PV}_{20}$ and $\mathrm{PV}_{40}$ formed complexes at N/P ratios of 3, 5 and 6 (Figure $1 \mathrm{Fd}-\mathrm{f}$ ). In the 1H NMR spectra (Figure 1G), all the peaks at 2.7-2.2 ppm belonged to chemical shifts of $\left(\mathrm{CH}_{2} \mathrm{CH}_{2} \mathrm{NH}\right)_{n}$ in PEIPDT; the peaks at $5.0 \mathrm{ppm}$ were assigned to $-\mathrm{NH}_{2}$ and those at 7.1-8.2 were attributed to pyridine. In the spectra of the PV copolymer, there still were signals of $-\mathrm{NH}_{2}$ and $\left(\mathrm{CH}_{2} \mathrm{CH}_{2} \mathrm{NH}\right)_{n}$ and new signals of $-\mathrm{CONH}-,-\mathrm{CH}_{2}$, and $-\mathrm{CH}_{3}$, indicating the VTW peptide, but pyridine signal disappeared, which meant that conjugation succeeded (Figure 1G).

\section{Transfection efficiency}

The scheme of the nanoparticle preparation and transfection of glioma cells is illustrated in Figure 2. U-87 was transfected with pEGFP nanoparticles complexed with PEI and PV separately. In general, with the U-87 cells, all the PV nanoparticles showed higher transfection efficiencies than the PEI nanoparticles, and the $\mathrm{PV}_{20}$ nanoparticles showed the best result $(68.59 \% \pm 2.13 \%)$ (Figures 3 and $4 \mathrm{~A})$. With the T98G and U251 glioma cells, the PV nanoparticles also showed better transfection results than the PEI nanoparticles, although not as good as the transfection results with U-87 cells (Figures 3 and $4 \mathrm{~B}$ and $\mathrm{C}$ ). The transfection efficiency of $\mathrm{PV}_{20}$ nanoparticles for the U-87, T98G, and U251 cells was still high, and even higher than with Lipofectamine (for U-87 cells) after adding serum to the incubation medium, although a little lower than without serum (Figure 4 A-C). Primary neural cells, A549 and PC12 cells, were transfected with $\mathrm{PV}_{20}$ nanoparticles as the control. As expected, the transfection efficiency of A549 and PC12 cells was not improved by PV $_{20}$ nanoparticles (Figures 3 and 4D). Furthermore, these nanoparticles did not show any effect on the transfection of primary neural cells from rat cerebral cortex (Figures 3 and 4D).

\section{Cytotoxicity of nanoparticles}

The cytotoxicity of PEI and PV nanoparticles was evaluated. All the PV nanoparticles exhibited less toxicity to U-87, T98G, 


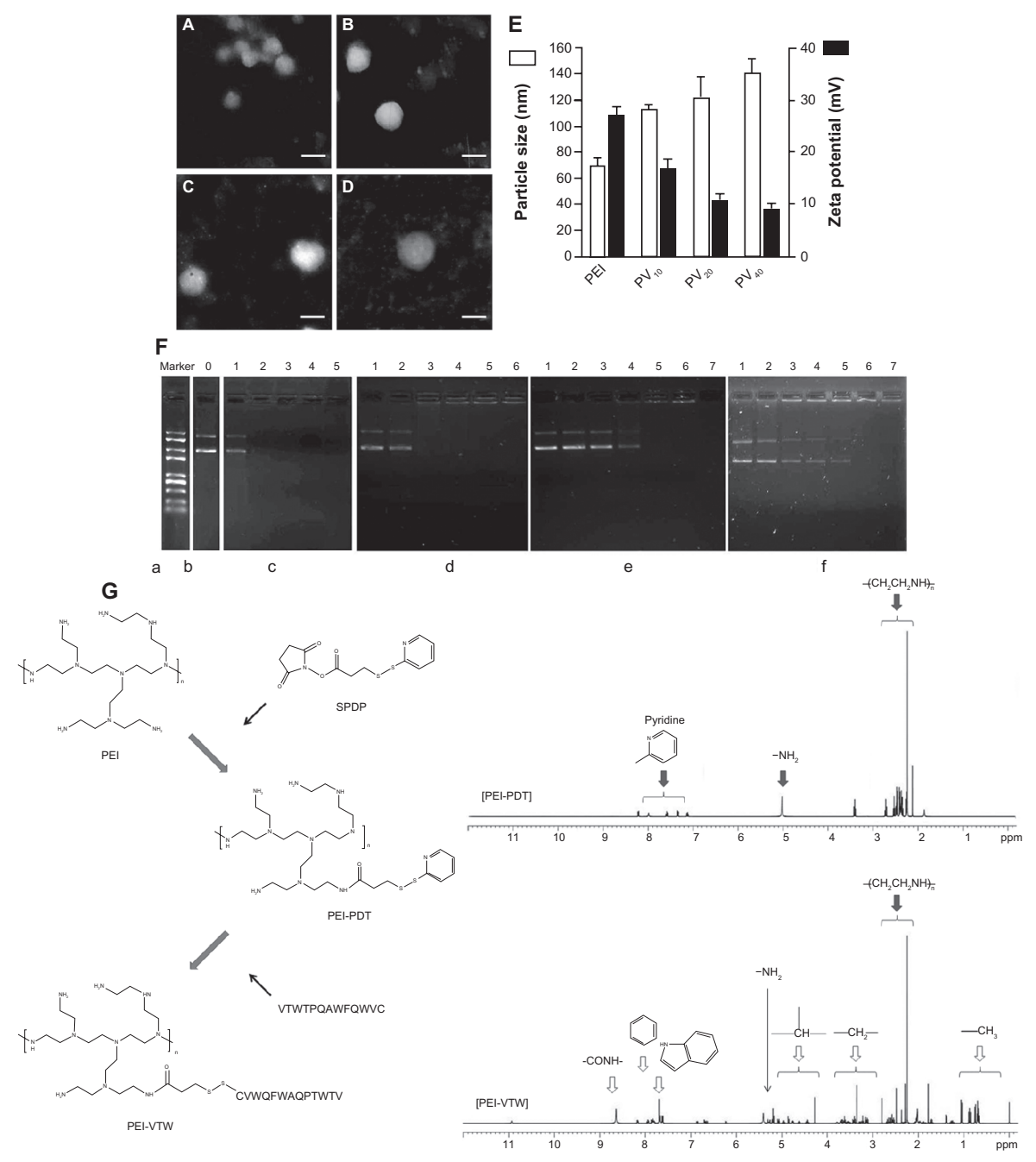

Figure I TEM, particle size, zeta potential, agarose gel electrophoresis, and NMR images.

Notes: All nanoparticles, PEI (A), PV 10 (B), $\mathrm{PV}_{20}(\mathbf{C})$, and $\mathrm{PV}_{40}$ (D), were made at an N/P of 10 (scale bar: $100 \mathrm{~nm}$ ). The detailed data of particle size and zeta potential are shown in (E). (F) shows the DNA ladder marker (a) and that PEl complexed DNA completely at an N/P of 2, PV 10 at $3, \mathrm{PV}_{20}$ at 5 , and PV 40 at 6 (b). The different results from gel electrophoresis of PEI (c), $\mathrm{PV}_{10}$ (d), $\mathrm{PV}_{20}$ (e), and $\mathrm{PV}_{40}$ (f) complexed with PDNA at various N/P ratios are shown. (G) shows the characterization of PV polymer by IH NMR spectra. The PEI was activated into PEI-PDT by SPDP, and then the PEI-PDT was conjugated with VTW peptide and made into PV.

Abbreviations: NMR, nuclear magnetic resonance; N/P, nitrogen in PEl amino residues to phosphates of DNA; PDT, pyridyldithio; PEI, polyethylenimine; PV, VTW-modified PEI copolymers; SPDP, N-succinimidyl 3-(2-pyridyldithio)-propionate; TEM, transmission electron microscopy; VTW, VTWTPQAWFQWV; pDNA, plasmid DNA.

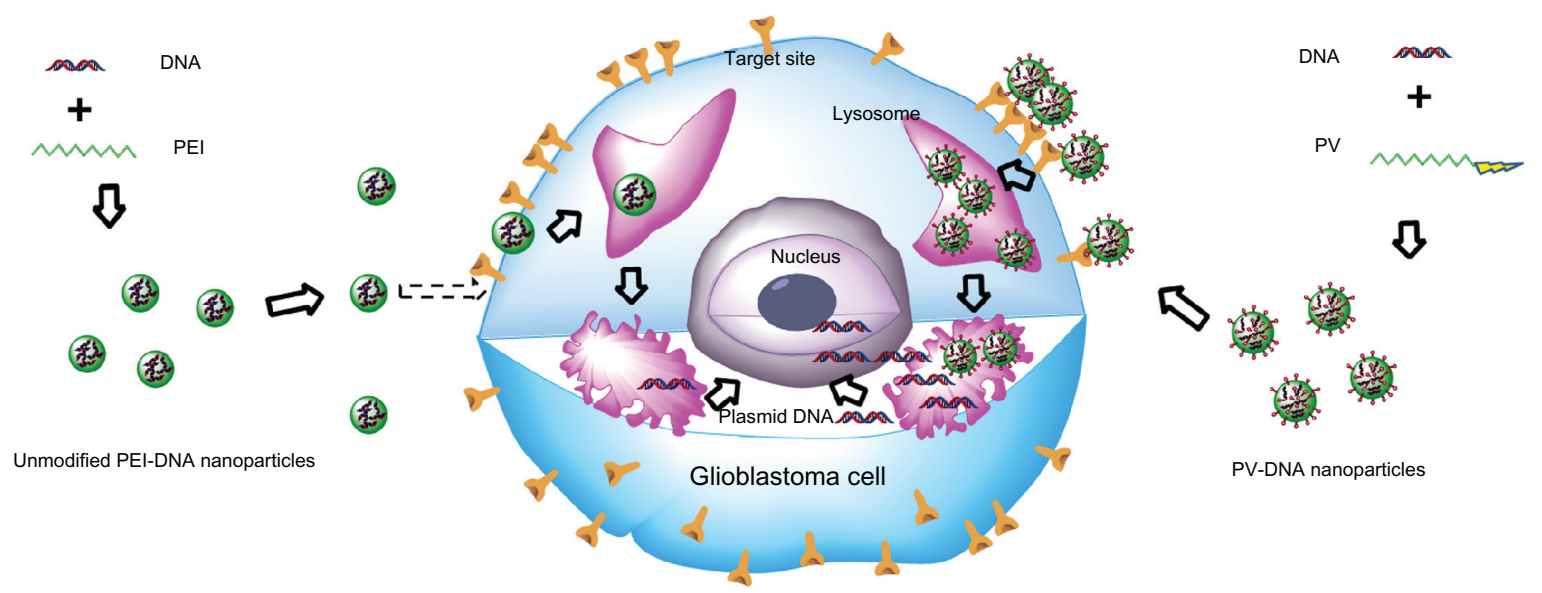

Figure 2 The synthesis of nanoparticles with plasmid DNA made of PEI or PV and their internalization. Abbreviations: PEI, polyethylenimine; PV, VTW-modified PEI copolymers; VTW, VTWTPQAWFQWV. 

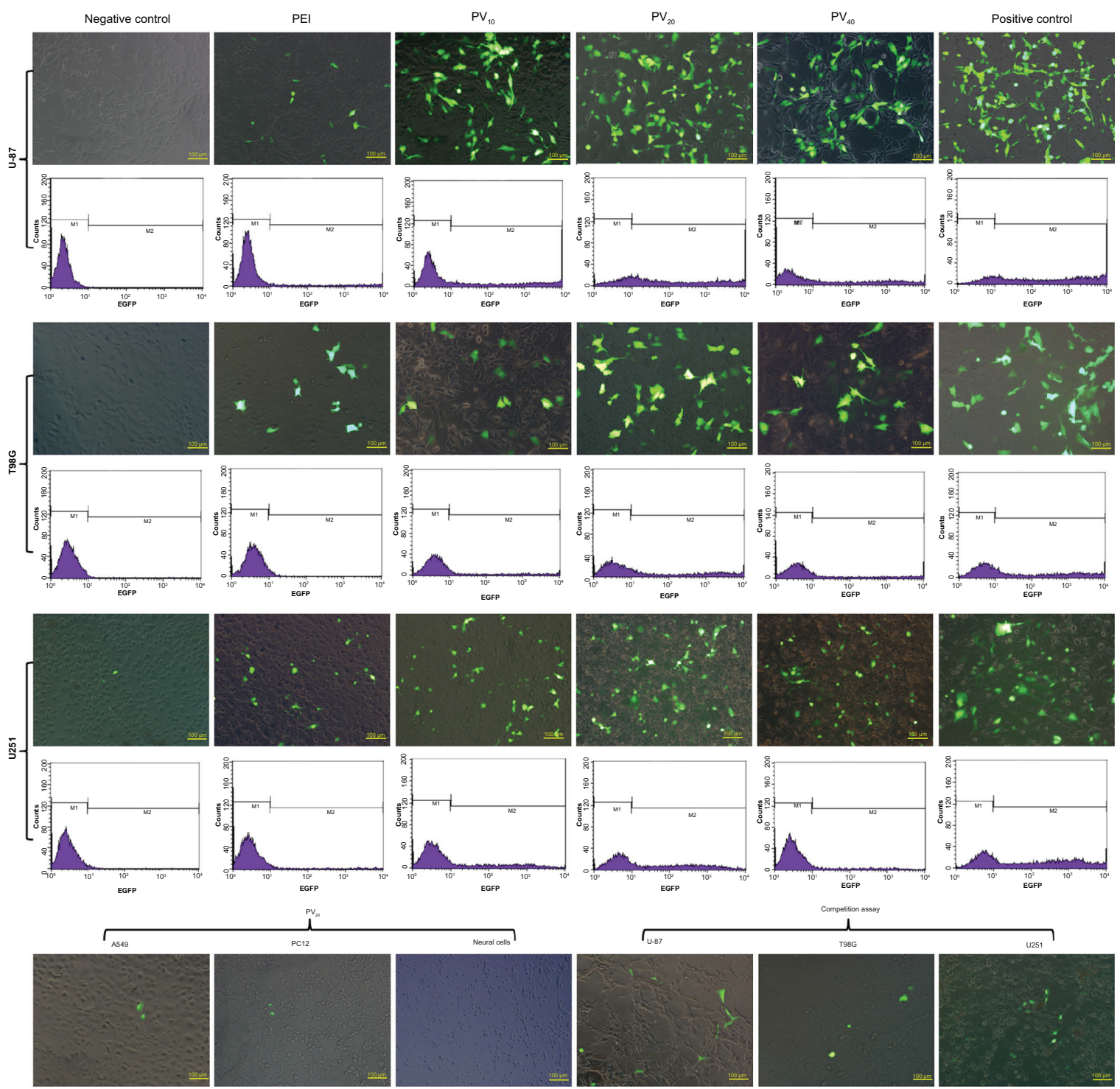

Figure 3 Transfection efficiency of nanoparticles for different kinds of cells.

Notes: Fluorescent micrographs and flow cytometry results of $\mathrm{U}-87$ cells transfected with $\mathrm{PV}{ }_{10}, \mathrm{PV}_{20}$, and $\mathrm{PV}$ 40 nanoparticles at the $\mathrm{N} / \mathrm{P}$ of $\mathrm{I} 0$ are presented. The transfection results of T98G and U25I are also shown. The fluorescent images were merged with optical ones. Negative control: naked pDNA; positive control: Lipofectamine ${ }^{\circledR}$ (Life Technologies, Carlsbad, CA, USA)-pDNA complexes. The $\mathrm{PV}_{20}$ nanoparticles showed very low transfection effect for PCI2 and A549 cells and absolutely no effect for neural cells. Competition assays for glioma cells are shown. Scale bar: $100 \mu \mathrm{m}$.

Abbreviations: N/P, nitrogen in polyethylenimine amino residues to phosphates of DNA; pDNA, plasmid DNA; PEI, polyethylenimine; PV, VTWTPQAWFQWV-modified PEl copolymers.

and $\mathrm{U} 251$ cells than the PEI nanoparticles (Figure 4A-C). The $\mathrm{PV}_{20}$ nanoparticles also had very low cytotoxicity to neurons compared with the PEI nanoparticles (Figure 4D).

\section{Internalization of nanoparticles}

In the cytoplasm of U-87 cells that were incubated with $\mathrm{PV}_{20}$ nanoparticles after 1 hour, there was colocalization of lysosomes and $\mathrm{PV}_{20}$ nanoparticles (Figure 5). After 4 hours' incubation, there was no obvious colocalization, which demonstrates good cellular uptake and escape from the lysosomes.

\section{Competition assays}

In competition assays, there was very low transfection efficiency in U-87, T98G, and U251 cells (Figures 3 and 4A-C) and no distribution of $\mathrm{PV}_{20}$ nanoparticles in U-87 cells (Figure 5), which means the uptake of $\mathrm{PV}_{20}$ nanoparticles into U-87 cells was nearly completely blocked after the cells were pre-incubated with free VTW peptide.

\section{Discussion}

GBM is a highly aggressive brain tumor in human beings, which is difficult to remove completely, prone to recur, 

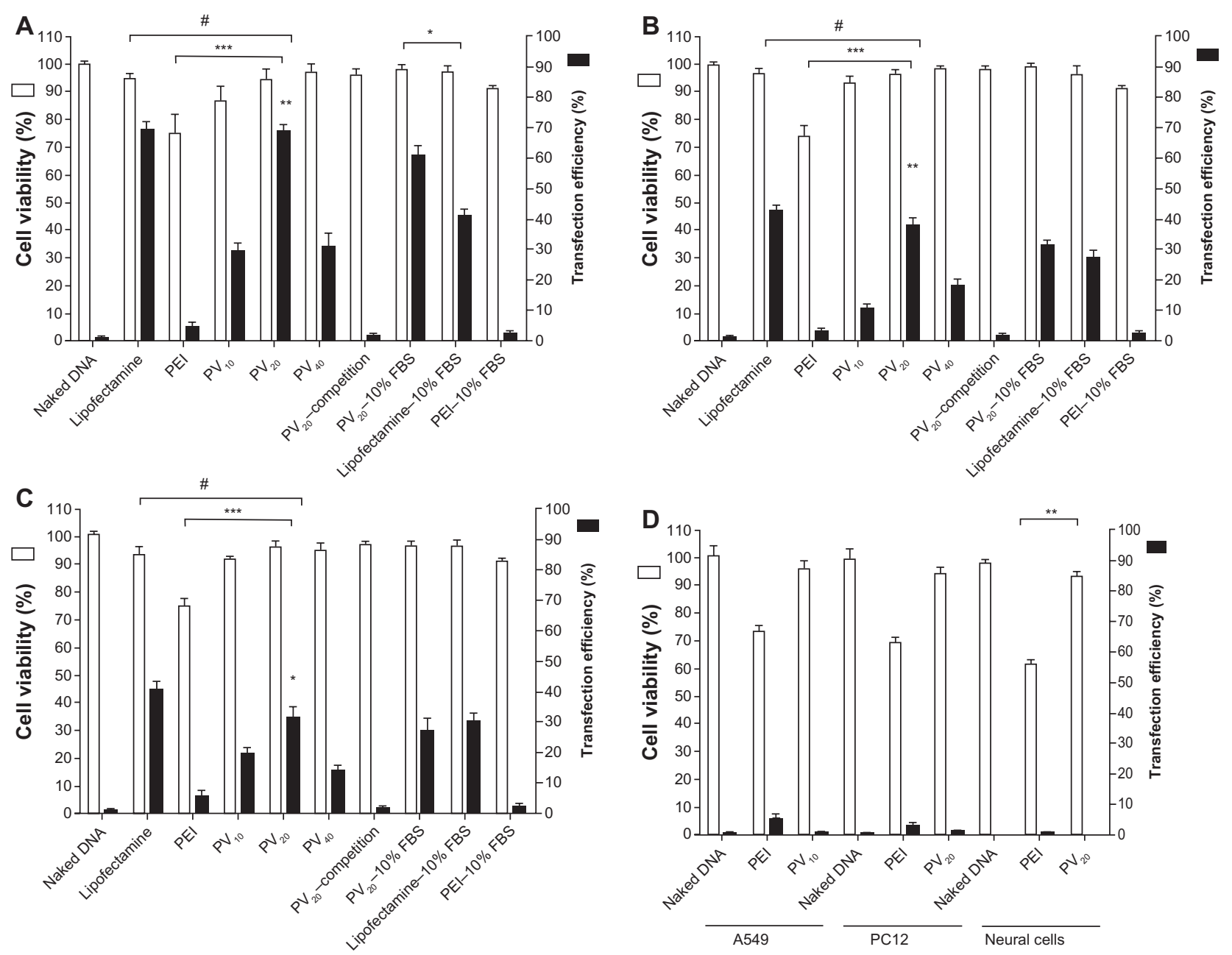

Figure 4 The histogram of the transfection efficiency and cell viability of different cells treated with nanoparticles.

Notes: (A) U-87 cells; (B) T98G cells; (C) U25I cells; (D) A549, PCI2, and neural cells. Negative control: naked pDNA; positive control: Lipofectamine ${ }^{\circledR}$ (Life Technologies, Carlsbad, CA)-pDNA complexes. The percent cell viabilities of different nanoparticles are shown. U-87 cells were transfected with all kinds of nanoparticles at the N/P of I0. The transfection efficiency of $\mathrm{PV}_{20}$ nanoparticles was better than the other PEl-based nanoparticles to U-87 and T98G cells (A and B) and U25I cells (C), and especially higher than that of the PEI nanoparticles to U-87 and T98G cells ( $\mathbf{A}$ and $\mathbf{B}$ ) and U25I cells (C). The transfection efficiency of PV ${ }_{20}$ nanoparticles to U-87 and T98G cells was close to that of Lipofectamine-pDNA complexes (A and B), a little lower than that of Lipofectamine-pDNA complexes to U25I cells (C). The PV 20 nanoparticles can resist the influence of serum very well, with higher transfection efficiency than Lipofectamine at the same condition (A). The competition assay showed the transfection efficiency to U-87, T98G, and U25I was all decreased significantly after the pre-incubation with free VTW peptide. The PV ${ }_{20}$ nanoparticles showed very low transfection effect to $\mathrm{A} 549$ and $\mathrm{PCI} 2$ and absolutely no effect to neural cells, meanwhile showing a very low cytotoxicity to neural cells compared with $\mathrm{PEI}$ nanoparticles. $* \mathrm{P}<0.05 ; * * \mathrm{P}<0.0 \mathrm{I}$; **** $<0.001 ; \# P>0.05$.

Abbreviations: FBS, fetal bovine serum; N/P, nitrogen in polyethylenimine amino residues to phosphates of DNA; pDNA, plasmid DNA; PEI, polyethylenimine; PV, VTWmodified PEI copolymers; VTW, VTWTPQAWFQWV.

and causes severe damage to the brain. ${ }^{1,4,5}$ Although gene therapy has been acknowledged as a promising strategy, there are still several disadvantages, ${ }^{3,5}$ including the need for specifically targeting the cancer cells..$^{25}$ It is a challenge to target and deliver genetic materials to GBM cells specifically. ${ }^{6,711,14}$ It has been reported that many carriers can augment the efficiency of introducing drugs or nucleotides into glioma cells..$^{20,26-29}$ One peptide, called VTW, which can selectively bind to GBM cells, indicates another promising approach. ${ }^{22}$ One report showed that the VTW peptide specifically increased the uptake of nitric oxide by GBM cells. ${ }^{30}$ In this study, we showed that the nanoparticles made of PEI and the VTW peptide significantly and specifically improved the transfection efficiency of GBM cells.

Many techniques, including purification, preparation, and chemical modification, have been used to improve the properties of nanoparticles. ${ }^{16,31}$ A heterobifunctional crosslinker, SPDP, has an amine-reactive radical called the $\mathrm{N}$-hydroxysuccinimide ester and a sulfhydryl-reactive radical called 2-pyridyldithio. ${ }^{32-34}$ This crosslinker guaranteed that PEI-PDT and VTW were conjugated accurately. DMF and $\mathrm{GnHCl}$ can act as a nonpolar cosolvent and increase the solubility of PEI-PDT conjugated with the VTW peptide. ${ }^{35-37}$ It is also important to note that the peptide solution should 

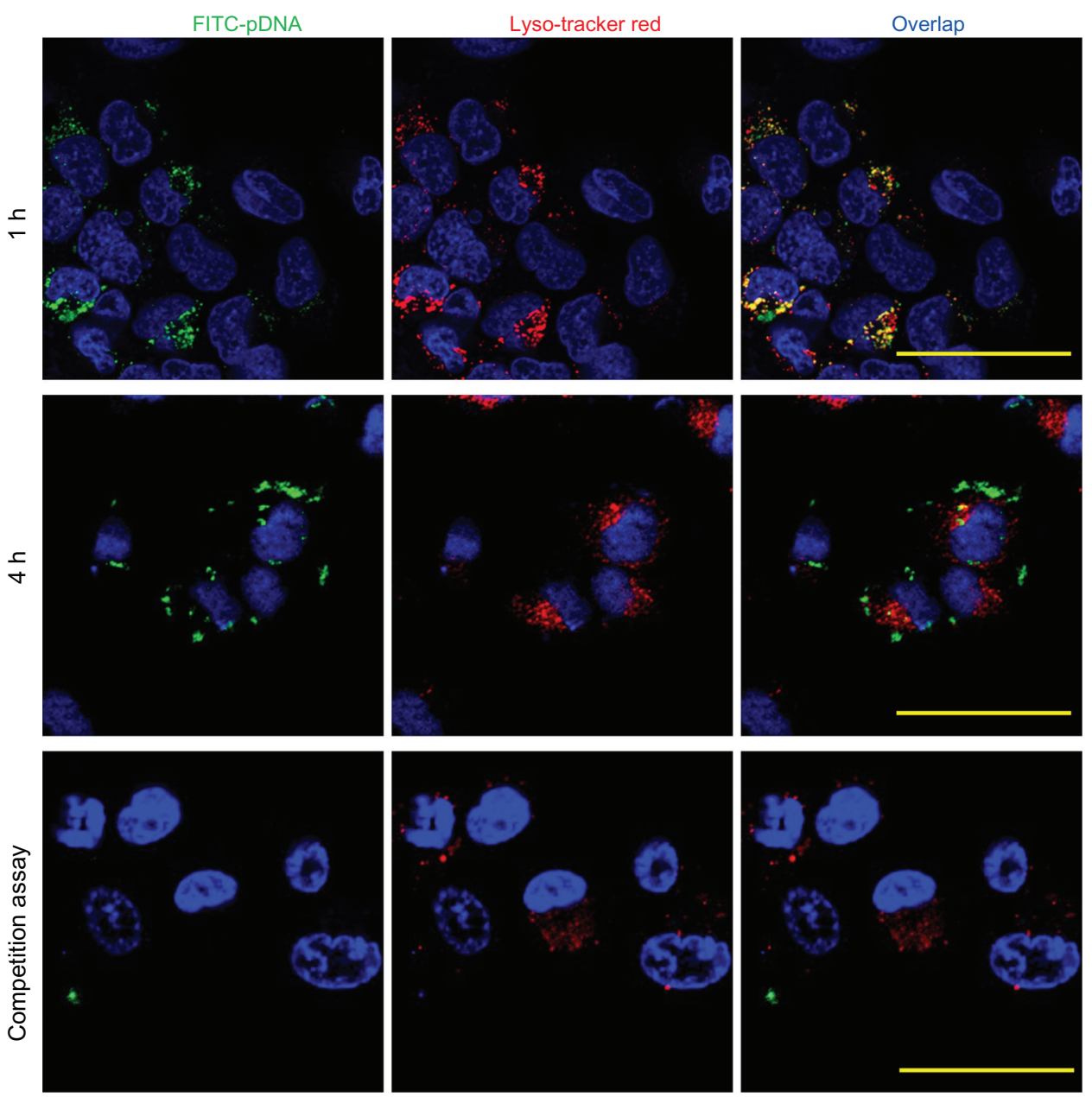

Figure 5 Internalization of nanoparticles.

Notes: U-87 cell was incubated with the $\mathrm{PV}_{20}$ nanoparticles containing the FITC-labeled pDNA. Lysosome was marked with Lyso-Tracker Red (Beyotime, Haimen, People's Republic of China) to investigate the location of nanoparticles in cytoplasm. The nucleus was stained with Hoechst 33342 (Beyotime, Haimen, People's Republic of China). Internalization assays showed that $\mathrm{PV}_{20}$ nanoparticles penetrated into U-87 cells, were mostly co-localized with lysosomes at I hour after the beginning of transfection, and escaped successfully from lysosomes at 4 hours. Competition assay showed there was very little internalization of PV ${ }_{20}$ nanoparticles in $U-87$ cells due to the block effect by free VTW peptide. Scale bar: $50 \mu \mathrm{m}$.

Abbreviations: FITC, fluorescein isothiocyanate; pDNA, plasmid DNA; PV, VTW-modified PEI copolymers; VTW, VTWTPQAWFQWV.

be slowly added to the PEI-PDT solution with constant vortexing to prevent local, temporary, high concentrations of the peptide. The peptide seemed to form a layer clinging to the surface of the PV nanoparticles, especially $\mathrm{PV}_{20}$ and $\mathrm{PV}_{40}$ (Figure 1 TEM images), which was thought to be the peptide linked with PEI. Due to this peptide-linked copolymer, the surface charge of the nanoparticles was reduced and the diameter was increased.

Successful transfection of polymer-based DNA nanoparticles depends on many factors, including cell internalization, escape from endosomes, DNA release from the nanoparticles, DNA entry into nucleus, and protein expression. Cell internalization is one of the most important parts of transfection, and it can be influenced by cell type, properties of the cationic polymers, size and charge density of the nanoparticles, and the endocytosis mechanism..$^{711,15,16,22,36}$
Receptor-mediated endocytosis can enhance the cellular uptake of nanoparticles. ${ }^{11,16,22,31}$ In our experiments, the U-87 cells could not be transfected effectively with unmodified PEI nanoparticles at an N/P ratio of 10 (Figures 3 and 4). In general, the VTW peptide facilitated the transfection of PEI nanoparticles into U-87 cells via receptor-mediated uptake, while it reduced the cytotoxicity (Figure 4) due to less residual positive charge on the surface of the nanoparticles. One study found that the VTW peptide may bind to gp 130 receptor in the glioma cells. ${ }^{22}$ Competition assays confirmed that the uptake of PEI nanoparticles is specifically mediated by VTW (Figure 5). When the molar ratio of VTW/PEI was 10 , the active targeting effect may not have been enough to increase the uptake of nanoparticles significantly, although the surface charge of the nanoparticles was still positive. When the ratio was 20, the VTW peptide was sufficient 
to promote the internalization of the nanoparticles but not enough to decrease the escape of the PEI nanoparticles from the lysosomes (Figure 5). However, a much higher ratio of VTW/PEI (eg, 40) might lead to instability of the nanoparticles and less DNA protection from PEI.

The transfection efficiency of $\mathrm{PV}_{20}$ nanoparticles for U-87, T98G and U251 cells was still good after adding FBS into incubation medium, and even better than Lipofectamine for U-87 cells. The transfection efficiency of the PEI nanoparticles was decreased when serum was present in the medium (Figure 4). This phenomenon showed that the $\mathrm{PV}_{20}$ nanoparticles can prevent the influence of serum, possibly due to the uncharged amino residues on the VTW peptide. Meanwhile, these nanoparticles also greatly increased the transfection efficiency for T98G and U251 cells, although not as much as for the U-87 cells (Figures 3 and 4). In the control, the VTW-based nanoparticles did not improve the transfection efficiency for A549, PC12 and the neural cells (Figures 3 and 4).

From another point of view, one previous report showed that there was an increase of DNA release from the acetylated PEI in transfection for cells, due to the acetylation of the amines in PEI. ${ }^{38}$ As such, we hypothesized that the release of pDNA from the $\mathrm{PV}_{20}$ nanoparticles may be more efficient, due to the replacement of the amines in PEI by peptides. This may be another reason to increase transfection efficiency. In addition, another property of VTW may promote transfection efficiency. VTW is an amphiphilic peptide, which contains eight uncharged, nonpolar amino acids and four uncharged, polar amino acids, ${ }^{22}$ hence the partially hydrophobic VTW peptide may make a closer link between the nanoparticles and the lipids of the U-87 cells after the nanoparticles are bound by the receptor on the cell membrane that specifically interacts with VTW. The $\mathrm{PV}_{20}$ nanoparticles presented approximately 14-fold higher transfection expression levels in U-87 cells than unmodified PEI nanoparticles, even as high as the effect of Lipofectamine $(P>0.05)$.

In short, the VTW peptide increased the transfection efficiency of nanoparticles and at the same time decreased the cytotoxicity, while the PEI component in copolymers increased the escape from lysosomes by its powerful sponge effect. Furthermore, although PEI is nondegradable in cells, considering the VTW has already targeted the PEI nanoparticles to the glioma cells specifically, leaving the neural cells unaffected, there is no need to be concerned about this. Furthermore, PV nanoparticles have an advantage over viral vectors, due to lack of dangers like the immunogenicity and potential oncogenicity of viral vectors. Our results show that the GBM cell-targeted $\mathrm{PV}_{20}$ nanoparticles had no transfection activity and almost no cytotoxicity towards the neural cells of rat cerebral cortex. This is good news for the potential use in vivo in future, but whether the nanoparticles are biocompatible when used in vivo is still unknown, and the transfection efficiency is still lower than that of viral vectors. Further studies will be aimed at making our nanoparticles more effective and more compatible in vivo.

\section{Acknowledgments}

This work was financially supported by the National Natural Science Foundation of China (Grant No 30872664) and Natural Science Foundation of Shandong Province, People's Republic of China (Grant No ZR2012HM107). The cell experiment assistance of the Cardiovascular Research Center of Qilu Hospital and the synthesis technical help from the School of Chemistry and Chemical Engineering of Shandong University are gratefully acknowledged.

\section{Disclosure}

The authors report no conflicts of interest in this work.

\section{References}

1. Deorah S, Lynch CF, Sibenaller ZA, Ryken TC. Trends in brain cancer incidence and survival in the United States: Surveillance, Epidemiology, and End Results Program, 1973 to 2001. Neurosurg Focus. 2006;20(4):E1.

2. Jukich PJ, McCarthy BJ, Surawicz TS, Freels S, Davis FG. Trends in incidence of primary brain tumors in the United States, 1985-1994. Neuro Oncol. 2001;3(3):141-151.

3. Das P, Puri T, Jha P, et al. A clinicopathological and molecular analysis of glioblastoma multiforme with long-term survival. J Clin Neurosci. 2010;18(1):66-70.

4. Tran B, Rosenthal MA. Survival comparison between glioblastoma multiforme and other incurable cancers. J Clin Neurosci. 2010;17(4): 417-421.

5. Lacroix M, Abi-Said D, Fourney DR, et al. A multivariate analysis of 416 patients with glioblastoma multiforme: prognosis, extent of resection, and survival. J Neurosurg. 2001;95(2):190-198.

6. Kew Y, Levin VA. Advances in gene therapy and immunotherapy for brain tumors. Curr Opin Neurol. 2003;16(6):665-670.

7. Germano IM, Binello E. Gene therapy as an adjuvant treatment for malignant gliomas: from bench to bedside. J Neurooncol. 2009;93(1): 79-87.

8. Yawata T, Maeda Y, Okiku M, Ishida E, Ikenaka K, Shimizu K. Identification and functional characterization of glioma-specific promoters and their application in suicide gene therapy. $J$ Neurooncol. 2011;104(2):497-507.

9. Guo DS, Wang BF, Han FX, Lei T. RNA interference therapy for glioblastoma. Expert Opin Biol Ther. 2010;10(6):927-936.

10. Mathupala SP, Guthikonda M, Sloan AE. RNAi based approaches to the treatment of malignant glioma. Technol Cancer Res Treat. 2006;5(3):261-269.

11. Morille M, Passirani C, Vonarbourg A, Clavreul A, Benoit JP. Progress in developing cationic vectors for non-viral systemic gene therapy against cancer. Biomaterials. 2008;29(24-25):3477-3496. 
12. Park JS, Na K, Woo DG, et al. Non-viral gene delivery of DNA polyplexed with nanoparticles transfected into human mesenchymal stem cells. Biomaterials. 2010;31(1):124-132.

13. Luten J, van Nostruin CF, De Smedt SC, Hennink WE. Biodegradable polymers as non-viral carriers for plasmid DNA delivery. J Control Release. 2008;126(2):97-110.

14. van Gaal EVB, van Eijk R, Oosting RS, et al. How to screen non-viral gene delivery systems in vitro? J Control Release. 2011;154(3):218-232.

15. Boussif O, Lezoualch F, Zanta MA, et al. A versatile vector for gene and oligonucleotide transfer into cells in culture and in vivo: polyethylenimine. Proc Natl Acad Sci U S A. 1995;92(16):7297-7301.

16. Lungwitz U, Breunig M, Blunk T, Gopferich A. Polyethylenimine-based non-viral gene delivery systems. Eur J Pharm Biopharm. 2005;60(2): 247-266.

17. Akinc A, Thomas M, Klibanov AM, Langer R. Exploring polyethylenimine-mediated DNA transfection and the proton sponge hypothesis. J Gene Med. 2005;7(5):657-663.

18. Frederiksen KS, Abrahamsen N, Cristiano RJ, Damstrup L, Poulsen HS. Gene delivery by an epidermal growth factor/DNA polyplex to small cell lung cancer cell lines expressing low levels of epidermal growth factor receptor. Cancer Gene Ther. 2000;7(2):262-268.

19. Li D, Ping YA, Xu FJ, et al. Construction of a star-shaped copolymer as a vector for FGF receptor-mediated gene delivery in vitro and in vivo. Biomacromolecules. 2010;11(9):2221-2229.

20. Kuo YC, Liang CT. Inhibition of human brain malignant glioblastoma cells using carmustine-loaded catanionic solid lipid nanoparticles with surface anti-epithelial growth factor receptor. Biomaterials. 2011;32(12):3340-3350.

21. Scott JK, Smith GP. Searching for peptide ligands with an epitope library. Science. 1990;249(4967):386-390.

22. Wu CX, Lo SL, Boulaire J, et al. A peptide-based carrier for intracellular delivery of proteins into malignant glial cells in vitro. J Control Release. 2008;130(2):140-145.

23. Brewer GJ, Torricelli JR. Isolation and culture of adult neurons and neurospheres. Nat Protoc. 2007;2(6):1490-1498.

24. Snyder SL, Sobocinski PZ. An improved 2,4,6-trinitrobenzenesulfonic acid method for the determination of amines. Anal Biochem. 1975;64(1):284-288.

25. Nair HB, Sung B, Yadav VR, Kannappan R, Chaturvedi MM, Aggarwal BB. Delivery of antiinflammatory nutraceuticals by nanoparticles for the prevention and treatment of cancer. Biochem Pharmacol. 2010;80(12):1833-1843.
26. Tzeng SY, Guerrero-Cazares H, Martinez EE, Sunshine JC, Quinones-Hinojosa A, Green JJ. Non-viral gene delivery nanoparticles based on poly(beta-amino esters) for treatment of glioblastoma. Biomaterials. 2011;32(23):5402-5410.

27. Shir A, Ogris M, Wagner E, Levitzki A. EGF receptor-targeted synthetic double-stranded RNA eliminates glioblastoma, breast cancer, and adenocarcinoma tumors in mice. PLoS Med. 2006;3(1):e6.

28. Castro MG, Candolfi M, Kroeger K, et al. Gene therapy and targeted toxins for glioma. Curr Gene Ther. 2011;11(3):155-180.

29. Candiani G, Pezzoli D, Ciani L, Chiesa R, Ristori S. Bioreducible liposomes for gene delivery: from the formulation to the mechanism of action. PLoS One. 2010;5(10):e13430.

30. Safdar S, Taite LJ. Targeted diazeniumdiolates: localized nitric oxide release from glioma-specific peptides and proteins. Int J Pharm. 2011;422(1-2):264-270.

31. Troiber C, Wagner E. Nucleic acid carriers based on precise polymer conjugates. Bioconjug Chem. 2011;22(9):1737-1752.

32. Barbet J, Machy P, Leserman LD. Monoclonal antibody covalently coupled to liposomes: specific targeting to cells. J Supramol Struct Cell Biochem. 1981;16(3):243-258.

33. Orlandi R, Canevari S, Leoni F, Mezzanzanica D, Ripamonti M, Colnaghi MI. Change in binding reactivity of an anti-tumor monoclonal antibody after the introduction of 2-pyridyl disulphide groups. Hybridoma. 1986;5(1):1-8.

34. Berthold PR, Shiraishi T, Nielsen PE. Cellular delivery and antisense effects of peptide nucleic acid conjugated to polyethyleneimine via disulfide linkers. Bioconjug Chem. 2010;21(10):1933-1938.

35. Chang JY. Structural heterogeneity of $6 \mathrm{M} \mathrm{GdmCl-denatured} \mathrm{proteins:}$ implications for the mechanism of protein folding. Biochemistry. 2009;48(40):9340-9346.

36. Lateef SS, Gupta S, Jayathilaka LP, Krishnanchettiar S, Huang JS, Lee BS. An improved protocol for coupling synthetic peptides to carrier proteins for antibody production using DMF to solubilize peptides. J Biomol Tech. 2007;18(3):173-176.

37. Roseman M, Jencks WP. Interactions of urea and other polar compounds in water. J Am Chem Soc. 1975;97(3):631-640.

38. Grigsby CL, Leong KW. Balancing protection and release of DNA: tools to address a bottleneck of non-viral gene delivery. $J R$ Soc Interface. 2010;7 Suppl 1:S67-S82.
International Journal of Nanomedicine

\section{Publish your work in this journal}

The International Journal of Nanomedicine is an international, peerreviewed journal focusing on the application of nanotechnology in diagnostics, therapeutics, and drug delivery systems throughout the biomedical field. This journal is indexed on PubMed Central, MedLine, CAS, SciSearch ${ }^{\circledR}$, Current Contents ${ }^{\circledR} /$ Clinical Medicine,

\section{Dovepress}

Journal Citation Reports/Science Edition, EMBase, Scopus and the Elsevier Bibliographic databases. The manuscript management system is completely online and includes a very quick and fair peer-review system, which is all easy to use. Visit http://www.dovepress.com/ testimonials.php to read real quotes from published authors. 